\title{
DA POBREZA DAS IMAGENS À MÚSICA DAS PALAVRAS
}

\author{
Denilson Lopes \\ UnB
}

\begin{abstract}
RES U M O
Podem os filmes aprender algo da literatura? Sem uma discussão teórica, o romance Onde andará Dulce Veiga? de Caio Fernando Abreu respondeu esta questão. Ele representa uma passagem do mundo do simulacro, cheio de imagens banais e jogos metatextuais, tão comuns nos anos 80, para um desejo de contar de novo estórias comuns, presente nos anos 90 . Sem negar as imagens midiáticas, uma narrativa contemporânea no cinema e na literatura é redefinida pela procura de uma escritura afetiva.
\end{abstract}

\section{Palavras-chave \\ cinema, literatura, Caio Fernando Abreu}

\begin{abstract}
A
capa de Onde andará Dulce Veiga? de Caio Fernando Abreu remete a uma representação fake. Bonecos de papel com que crianças em outras eras menos tecnológicas se divertiam. Aparece supostamente a própria Dulce, ladeada por onças e palmeiras. A mistura entre o artifício e o mau gosto ganha um suporte no subtítulo: romance B. O que não deve ser entendido como mero elogio do trash, do lixo, de um deboche que reúne desde o cinema marginal até o fascínio de certo público jovem que ri de filmes de terror mal feitos. Há menos um deboche do que um olhar que não pode ser virgem diante do mundo das imagens. Ecoa o bordão dos velhos anos 80: tudo já foi dito, só podemos falar de cinema ou de literatura. Mas o passado nunca volta tal qual ele foi, restam ruínas de cenários já usados em filmes A, citações que tiveram outros sentidos. Obras-primas e medianas se misturam e se constituem num imenso "museu imaginário", para usar o termo conhecido de Malraux, mas o que mais me fascina é o que vai além do simples imobilismo de ser um espectador do mundo.

Há um sutil contraponto entre o subtítulo, a estética B, e as epígrafes, no início e no fim do romance. A primeira, de John Fante, remete à pobreza material e à fragilidade do escritor. Evocando deus e um escritor, o começo do livro é um ato de necessidade, de vida e de fé: "Please God, please Knut Hamsum, don't desert me now. I started to write and I wrote" (p.7). ${ }^{1}$ A escrita como uma necessidade se traduz
\end{abstract}

${ }^{1}$ Por favor Deus, por favor Knut Hamsum, não me abandonem agora. Eu comecei a escrever e eu escrevi. 
no próprio movimento existencial do protagonista: "Eu precisava falar de Dulce Veiga. Dela, de mim, do tempo" (p.30). O livro termina com Clarice Lispector, novamente pedindo auxílio: "Ah Força do que Existe, ajudai-me, vós que chamam de o Deus" (p.215). Poderíamos pensar numa saída de redenção do mundo, mas paira uma dúvida se esta possibilidade de redenção ainda é possível. Em meio a esta dúvida, a escrita se faz, o protagonista-jornalista busca voltar a escrever "ao querer desesperadamente dar forma através de palavras a algo que só existe, sem face nem nome, nessa região longínqua do cérebro onde a fantasia cruza com a memória e a intuição cega" (p.54).

As imagens mais cinematográficas e menos televisivas são o horizonte de constituição do mundo do protagonista, de sua forma de ver o mundo. Gradualmente, um mundo desencantado vai se reencantar, as imagens não são só internalizadas, mas afetivizadas, para além de uma inflação metatextual. Resta saber se este encantamento ainda está sob o signo do artifício, mesmo no final. Ou ainda, o afetivo está predestinado ao clichê? ${ }^{2} \mathrm{O}$ tempo faz de tudo um lugar comum?

A dedicatória feita a todas as cantoras do Brasil pode nos dar uma pista. Dulce Veiga nunca existiu mas parece uma síntese das damas da MPB e do cinema clássico hollywoodiano, ora mulher fatal de filme noir, ora heroína melodramática. O título do romance de Caio é também o título do livro-reportagem (p.106) que o patrão do protagonista sugere sobre Dulce, a cantora desaparecida vinte anos atrás, quando justamente ia fazer o show que a colocaria entre os grandes nomes da música popular, deixando de ser só uma cantora cultuada por poucos.

O livro poderia ser situado num intervalo entre romance e jornalismo, traduzindo, a partir de diferentes depoimentos, a ascensão e queda de um ícone contemporâneo, procedimento recorrente, desde o clássico Cidadão Kane de Orson Welles até Velvet Goldmine de Todd Haynes. Mas sobretudo num filão que vai refletir sobre a presença das divas e de suas existências trágicas, fora das telas, longe dos palcos. É só lembrar das várias versões de Nasce uma estrela. Ou entre nós, Ester Góes em Stelinha, Betty Farias em A estrela sobe e a atriz decadente que Marília Pera interpreta em Anjos da noite. ${ }^{3}$

A diferença com os filmes brasileiros contemporâneos é que neste romance de Caio, a diva, responsável por uma presença aurática em meio a uma sociedade marcada pela reprodutibilidade técnica e eletrônica das imagens, não fica apenas como um objeto de culto, ser por excelência do mundo do simulacro, em que imagens e realidade não se dissociam. O romance de Caio é um elo entre os pastiches e as metaficcões que saturaram os anos 80 e o desejo de narrativas simples, despojadas de referências

\footnotetext{
${ }^{2}$ Vai ao encontro do que Eucanãa Ferraz fala sobre Morangos mofados: "O subliterário e o lugarcomum contaminam a escrita de tal modo que já não podemos diferenciar com total segurança a ironia, a paródia e o puro fluxo do pensamento, despido então de travas seletivas, e, quanto mais intenso e apaixonado, mais propenso a um amplexo que generosamente abraça e aceita a contribuição milionária de todos os clichês, desde que possam exprimir um desejo, uma verdade, um espinho íntimo". Cf. FerRAz. Morango com creme.

${ }^{3}$ Uma constante na obra de Guilherme de Almeida Prado, a quem também o livro de Caio é dedicado. A presença de Caio tem outras curiosidades. Ele aparece como figurante em Perfume de Gardênia. Sua personagem Dulce Veiga é mencionada em A hora mágica. Um exemplar de sua peça Maldição do Vale Negro também aparece em cena. Retribuição da dedicatória ou uma afinidade artística maior?
} 
explícitas. Não se trata de um fascínio vazio, mas de uma busca desesperada de sentido e afeto num mundo empobrecido. $\mathrm{O}$ que começa como simples obrigação profissional, a procura de Dulce Veiga, traduz-se num acerto de contas com o passado. Foi com ela que o protagonista fez sua primeira entrevista. É também nessa procura policialesca que seu passado afetivo vai se constituindo como questão ética.

O protagonista é apresentado, na segunda-feira, quando vai começar um novo trabalho. Jornalista, de meia-idade, autor de um livro de poemas que ninguém leu, descrente em si e no mundo, sozinho, sem amigos (p.74), pouco sexo, pouco amor (p.76), morando num apartamento minúsculo (p.11), de um "edifício doente, contaminado, quase terminal" (p.37), vivendo numa São Paulo "infernal" (p.11), sufocante (p.16), à beira da explosão (p.81). Uma vida em crise, em que o simples ato de conseguir emprego num jornal de quinta categoria é visto por ele como um milagre.

Este mundo empobrecido, em que a presença da AIDS aparece como uma metáfora de personagens infelizes, é marcado por uma construção cinematográfica, repleta de clichês, lugares-comuns, simulacros e é redimido pela música como possibilidade de recuperar uma memória, uma possibilidade de afetividade, de sublime, de pertencimento ao presente. A cidade doente é também o espaço de uma busca. Não mais o tom libertário de outros momentos, como em "Anotações sobre um amor urbano" (em Ovelhas negras): "Não vê que é isso que eles querem que você sinta? medo, culpa, vergonha - eu aceito, eu me contento com pouco - eu não aceito nada nem me contento com pouco - eu quero muito, eu quero mais, eu quero tudo" (p.205). Há o desejo de desaparecer como Dulce Veiga: "Eu não tinha nada especial. (...) Uniforme de guerra, ou de quem quer ficar invisível. E eu queria, há tanto” (p.23). Aos poucos, ir além de sobreviver, do se negar. É uma outra invisibilidade que vai surgir, não esta negação, esta ausência.

Mais singular é a forma como a questão ética - o que fazer? - se articula desde o início com a música. "Eu deveria cantar. Rolar de rir ou chorar, eu deveria, mas tinha desaprendido essas coisas" (p.11). O uso do verbo dever ressalta não uma obrigação, mas uma necessidade, uma premência. E o não saber cantar é associado a esta perda de expressar sua afetividade: "Eu sorri. Quer dizer, contraí os músculos da face para mostrar os dentes" (p.16) e “...ternura, sensibilidade, emoção: eu não gostava nem um pouco dessas palavras” (p.83). Trata-se de reaprender a sentir, a acreditar, sem idealização, nem cinismo. Estar à margem sem vitimização, ainda quando estes sentimentos sejam justos. O ressentimento é um veneno maior para quem o sente do que para quem o causa. Não desistir, mesmo diante do cansaço. Posicionar uma voz, mas não ter a voz. O protagonista sem nome sente uma nostalgia de outros tempos em que tinha fé e alegria, reage à pose, à afetação, recusa um mundo referencializado e vigiado pelo cinema: "Sem juiz nem platéia, sem close nem zoom" (p.11). Mas ao buscar negar o simulacro, nasceria uma outra pose, a da autenticidade? Não importa. Há muito a cultura pop constitui nossos afetos e vivências. Não há nada escandaloso, nem é simplesmente colonização do imaginário, é só cotidiano o cruzamento das fronteiras ente erudito, pop e popular. O que importa talvez seja o imperativo da alegria (p.12), na deriva entre um real "sem nada por trás além dele mesmo"(p.40), "bem menos retórico", direto, o mundo de fatos jornalísticos, sem afeto, sem memória, imagens substituindo umas as outras, parecendo com outras, e o mundo da ilusão. 
Como diz uma música: "A realidade não importa, o que importa é a ilusão" (p.13). Mundo repleto de lembranças. $\mathrm{O}$ invisível revelado pela música. $\mathrm{O}$ cinema reafirma a banalidade do mundo da cidade, "chatíssimo roteiro" (p.13), transformada em imagem, ao mesmo tempo, caos e diversidade. É a música, ouvida no cotidiano ou lembrada, a presença de Dulce Veiga é que vão dar um foco ao personagem, afetivizando o mundo da informação. Quando ouve uma música pelo rádio é que se coloca o desafio de como mergulhar no passado sem voltar com clichês, como contar esta estória, como viver esta vida.

É possível contar a estória de alguém? "Perdera o vício paranóico de imaginar estar sendo sempre filmado ou avaliado por um deus de olhos multifacetados (...), mas não o de estar sendo escrito" (p.12-3). Poderia a escrita ainda conseguir o que as imagens não conseguem mais? Não se trata da afirmação do papel da escrita contra as imagens, mas simplesmente uma forma de o protagonista voltar a escrever, sem temor da afetividade, do seu ridículo, do seu mau gosto, da sua pobreza. Uma escrita não mais associada à dor, nem fruto da dor (p.53).

A voz ouvida no rádio é reconhecida depois, voz de Márcia Felácio, vocalista da banda Vaginas Dentatas, filha de Dulce Veiga, "voz de vidro moído, áspera e aguda, girando dentro de um liqüidificador, nem feia nem desafinada, mas incômoda na maneira como ocupava espaço dentro do cérebro da gente, aquela voz que, independente do que cantasse, dava a impressão de sair do fundo de ruínas atômicas, não as ruínas falsificadas daquele cenário de papelão, mas as de Hiroshima, as de Köln, depois do bombardeio" (p.27). Márcia, nova diva, "sereia radioativa" (p.27), canta "Nada além", canção que Dulce também cantava. Novamente, o protagonista move os lábios, mas não canta (p.27). A felicidade estaria só na ilusão momentânea de uma música? Dulce volta pela imagem da filha.

No limite, não sei como proceder, ou me encanto ou vejo a ironia. Mas aqui, o humor nunca nega a afetividade. Não resisto à imagem de Dulce Veiga, na sua aparição, "toda vestida de vermelho, uma rosa branca aberta, presa na gola do casaco" (p.30), toda composta numa pose, feita para ser vista, contemplada, mesmo que não houvesse ninguém para ver. "Como se depois de todos aqueles anos, esperasse por mim" (p.31). E que termina por desaparecer após um raio de prata (p.31).

Dulce Veiga, a melhor de todas. A mais elegante, a mais dramática, a mais misteriosa e abençoada com aquela voz rouca que conseguia dar forma a qualquer sentimento, desde que fosse profundo. E doloroso, Dulce cantava a dor de estar vivo e não haver remédio nenhum para isso. E era linda, tão linda. Não só a voz, mas a maneira como se debruçava sobre o piano com um cálice de dry-martini na mão, mexia lenta a azeitona e pegava devagar o microfone com a outra. Não, por favor, não pense nenhuma vulgaridade (p. 48-9).

Fascínio é o que pede Castilhos, diretor do Diário da Cidade, ao protagonista, a nós leitores. É algo para além da relação desigual e de adoração estabelecida entre fã e ídolo. O caráter mágico e religioso que vai constituir o culto às estrelas de cinema, na análise clássica de Edgar Morin, pode dar uma sugestão do que está em jogo. Do cinema mudo até os nossos dias, a indústria de imagens reproduzidas tecnicamente inundou o planeta com uma quantidade nunca antes vista de informação rápida. É uma verdadeira proeza se manter no topo. A indústria é voraz, descarta pessoas como 
fatos envelhecidos. Por isso, a surpresa, uma cantora desaparecida há vinte anos suscita emoções ocultas e inesperadas em Castilhos, na contracorrente do esquecimento. Refulge fragilmente uma lembrança, um momento, estrelas que lembram um passado. Fala o protagonista: "De repente, lembrei de Jayne Mansfield nos bailes do Copacabana Palace, eu era muito antigo. Ou não havia mais estrelas, como antigamente" (p.144).

Uma das aparições de Dulce conduz o jornalista ao pianista que a acompanhava, Pepito Moraes. A fantasia e o acaso emolduram a realidade e o encontro do que se procurava, mesmo que se encontre uma outra coisa. Não há lógica racional, engenhosa a ser descoberta, como em romances policiais tradicionais, em que o mistério é revelado no fim, o criminoso punido. A ambiência é noir, mas há algo além. As aparições camp de Dulce oscilam entre um recurso banal de filme policial e o sublime no cotidiano, o sublime no artificial. "Faz mal lembrar das coisas que se foram e não voltam" (p.65), fala Pepito, agora pianista de bar. Para o protagonista, "o pior não seria nunca a morte real, o nada e o nunca, pior era não lembrar, não poder ou não querer lembrar” (p.69). "Tudo aquilo que eu esquecia ou negava, soube vagamente, em plena queda, era o que eu mais era" (p.69), como estava escrito num poema de Cecília Meireles, enviado por Lídia, sua ex-companheira. Esta lembrança que tentava esquecer, revelava "um vazio que nem todas as obscenidades que Jacyr continuava dizendo poderiam preencher, tornar engraçado ou mais leve, dentro daquela saudade que não ia embora por mais que o tempo passasse e dentro dele, mesmo sem lembrar, apenas agindo" (p.78). Um "dia de cão" o tira da autocomiseração, evita que ele momentaneamente se lembre do que não queria lembrar (p.79).

A lembrança de Dulce vem como "num filme qualquer, em preto e branco, da década de 40 ou começo dos 50" e, como fundo musical, a voz de Billie Holiday (p.33). Há um desejo de pureza, de uma imagem forte, mas irremediavelmente no passado. "Tudo isso que agora parece clichê banal, naquele tempo — repito e não me canso, porque é belo e mágico na sua melancolia: naquele tempo - tudo era novo, eu nem suspeitava das marcas pelo caminho" (p.34), relembra o protagonista da primeira entrevista que fizera, justamente com Dulce Veiga.

A entrevista é um encontro de duas vidas, como o que acontece com Márcia. Sem nostalgia, Márcia parecia compor sua vida, "futura cinebiografia de artista quando jovem". "Ela soava falso ao contar essas coisas, mas essa falsidade, percebi aos poucos, não passava de um jeito de esconder a emoção, porque no fundo, além de todos os filtros glamourosos, alguma coisa daquela história verdejante devia mesmo ser verdadeira. Pelo menos, a voz dela, às vezes, era realmente assim como buscara" (p.93). Nesse ato de se falar para outro, no que pode haver de falso, montado, composto, se revela a verdade do jogo, do simulacro da subjetividade e da confissão.

Através do fascínio por Márcia, mas sobretudo por Dulce, por sua voz, o passado conduz o protagonista no resgate do que foi perdido, encarnado sobretudo na lembrança de Pedro. Com um mês separado de Lídia, acontece Pedro. As oscilações das escolhas sexuais do protagonista, que de resto ecoa com a transitividade de gêneros, a ambigüidade de outros personagens, não impede que falemos de homossexualidade, recusada numa fala de Márcia como limitadora (p.168), mas certamente se trata de uma homoafetividade. ${ }^{4}$ Ao lembrar Pedro, não se trata de esconder a homossexualidade

${ }^{4}$ Ver em "Escritor, Gay". 
atrás de uma pansexualidade difusa, que reafirma preconceitos. É a partir desta homoafetividade que emerge uma experiência, uma ética e estética da amizade, ${ }^{5}$ fundadas não a partir de códigos morais impostos e universais, mas condutas e modos de vida particulares, mas sobretudo um caminho mesmo para um sublime ou mesmo uma espiritualidade homossexual.

Se a fragilidade institucional e histórica da amizade entre homens é decorrente do Cristianismo e seu pânico da homossexualidade, ${ }^{6}$ esta relação, atualmente, não é um artifício compensatório, um ornamento afetivo a que reservamos um lugar espremido e residual entre as obsessões amoroso-sexuais e os deveres cívicos; representa algo inquietante e perigoso, que possui um caráter inesperado e intenso, jogo agonístico e estratégico, ${ }^{7}$ nunca uma coisa dada no presente, ela faz parte da experiência da espera, da promessa ou do compromisso, ${ }^{8}$ não exclui o desejo sexual, ${ }^{9}$ tornando-se um espaço de constante experimentação e, ao mesmo tempo, uma base para positivar os encontros casuais e curtos, bem como para apreender uma gama enorme de sentimentos, necessidades e redes afetivas que se formam para além ou no lugar da família patriarcal ou nuclear urbana.

A identidade se traduz em, se define por experiências: "O beijo de Pedro não era desses de amigo bêbado, encharcado de álcool e solidariedade masculina, carência etílica ou desespero cúmplice. A língua de Pedro dentro da minha boca era a língua de um homem sentindo desejo por outro homem" (...) "Eu gostava de mulher, eu tinha medo. Todos os medos de todos os riscos e desregramentos" (p.113). Do pouco e mau prazer com as mulheres à alegria: "Só alegria, eu senti com Pedro. Uma alegria que era o avesso daquela que tinham me treinado para sentir" (p.115). Quando Pedro sumiu, "desde esse dia, perdi meu nome. Perdi o jeito de ser que tinha antes de Pedro, não encontrei outro. Eu queria que voltasse, não conseguia viver outra vez uma vida assim sem Pedro. (...) Parei de trabalhar. Parei de ser e de fazer qualquer outra coisa além de esperar que ele voltasse. Mas Pedro não voltou, eu não voltei” (p.116). Pedro e Dulce voltam não como no passado, mas para serem outros. A lembrança de Pedro não o traz de volta. Ele pode até ter morrido. O protagonista tem que aprender a viver, e não só a sobreviver, sem Pedro. É diante de Dulce, no fim, que este aprendizado

\footnotetext{
${ }^{5}$ Ver o romance Aimer de René de Ceccatty ou a fotógrafa Nan Golding falando de sua "família de amigos" que ela retratou por anos e anos numa espécie de diário visual: "Pessoas partem. Pessoas retornam, mas estas separações não são rupturas na intimidade. Nós estamos ligados não por vínculos de sangue, nem pelo lugar, mas por uma moralidade semelhante, a necessidade de viver a vida completamente e no presente, uma descrença no futuro, um respeito pela honestidade, uma necessidade de quebrar limites e uma história comum. Nós vivemos uma vida sem levá-la a sério, mas levando-a a sério. Há entre nós uma habilidade em ouvir e compartilhar que ultrapassa a definição normal de amizade". Golding. The ballad of sexual depedency, p.6-7.

${ }^{6}$ Eribon. Michel Foucault e seus contemporâneos, p.200.

${ }^{7}$ Costa. Prefácio, p.11-12.

${ }^{8}$ Derrida citado por Ortega. Para uma política da amizade, p.7.

9 "O problema não é de descobrir em si a verdade do sexo, mas sobretudo de agora em diante usar a sexualidade para chegar a multiplicidades de relações. É esta, sem dúvida, a razão pela qual a homossexualidade não é uma forma de desejo mas algo de desejável. Portanto, nós devemos nos bater para nos tornar homossexuais e não nos obcecar para reconhecer que o somos. É nesta direção que vão os desenvolvimentos do problema da homossexualidade: o problema da amizade." FouCAULT. De l'amitié comme mode de vie, p.163.
} 
se afirma. Mas o seu sentido é como um exercício de meditação, em que o essencial é vivenciado, não transmitido. O leitor deve, se quiser, ser tocado.

Durante todo o romance, aparece o fascínio do protagonista pela música e por Dulce Veiga, que o tira de um certo mal-estar, ainda que o fato de não saber cantar retorne (p.76). Se as aparições de Dulce o retiram, às vezes, de situações em que o sexo pode acontecer (com Filemon, nas p.59-61, ou na conversa com o jovem português no bar, na p.135), trata-se menos de fuga do que posicionar o desejo em outro foco. Dulce Veiga representa, ao mesmo tempo, algo que ele não tem, talvez tenha tido, e algo que pode acontecer quando menos se espera. Algo belo, algo importante. Algo oculto. Não é à toa que na procura jornalística e memorialista atrás de Dulce, é o nome de Pedro que vai aflorar também pouco a pouco.

A associação entre Dulce Veiga e Pedro, a diva e seu grande amor, não só afetiviza um ícone do universo pop(ular) mas dramatiza, espetaculariza um encontro privado. As aparições fantasmagóricas de Dulce Veiga na cidade se equivalem às lembranças de Pedro. Umas e outras se indissociam. Amar Pedro. Amar Dulce. Algo se perdeu. Ao lembrar quando Dulce desaparecera, o protagonista se pergunta onde andaria naquela época (p.56). Algo pode ser reconquistado? Não se trata de proceder o luto, mas reavivar mais o passado até que sua força passada lance a beleza sobre o presente, lance perspectivas sobre o desamparo.

Estrelas, lembranças, pessoas. Não resisto também a Pedro. "Pedro era tão claro que, no escuro, quando estava nu, eu ficava olhando para ele à espera de que sua pele fosforescesse como roupa branca na luz negra" (p.100). Tanto Pedro como Dulce se descorporificam, perdem em materialidade e ganham em espiritualidade. Em Dulce Veiga, não só está uma homenagem às cantoras do Brasil, mas a cada gesto seu, ecoam imagens, a que o protagonista não resiste associar a Isabella Rosselini e seu charme cult (p.55) ou a Rita Hayworth em Gilda com seus cabelos louros, a Silvinha Telles (p.57) ou a uma espiã de filme dos anos da Guerra Fria (p.62). Dulce retorna em fragmentos, imagens e frases, como Pedro. $\mathrm{O}$ canto para Dulce, segundo sua provável última entrevista, cria um sentido, embora seja inútil. $O$ canto, numa sociedade mercantilizada, traz vantagens materiais, mas Dulce procura uma outra coisa, "maior que eu mesma ou que qualquer canção" (p.56).

Da obtenção do emprego, como mudança do "pântano de depressão e autopiedade onde refocilava há quase um ano" (p.12), ao encontro com Dulce Veiga, objetivo de seu artigo, o protagonista religa seu passado a um vislumbre de futuro. Na parte final, mais curta e sintética do livro, a realidade de Estrela do Norte, no centro do Brasil, se apresenta quase mágica. A presença do caos paulistano e das referências cinematográficas cedem lugar a uma comunidade esotérica, onde o protagonista toma uma bebida para relaxar. Duas irrealidades? Duas fugas? Duas possibilidades de sobrevivência, de busca de alguma alegria, alguma beleza. Da sobrevivência ao encantamento. $\mathrm{O}$ ciclo se fecha em aberto. $\mathrm{O}$ impasse persiste, mas houve um caminho, encontros e desencontros, uma experiência foi constituída. Não mais só "confundir experiência e devastação" (p.12), mas relatar nossa experiência da guerra cotidiana, ultrapassar um silêncio que insiste em nos desqualificar, nos isolar. ${ }^{10}$ Não mais só imagens

${ }^{10}$ Cf. Benjamin. Experiência e pobreza. 
alucinadas, em êxtase ou entediantes. Algo mais. Nada além. Desejo de desaparecer no anonimato. Desejo de ser invisível na multidão das diferenças, como o de Dulce Veiga de desaparecer, numa fala inesperada, na sua última entrevista (p.56). Aprender a só ser. "Fechei a gaveta, eu não podia lembrar. Era preciso encontrar Dulce Veiga, manter aquele emprego, continuar a viver. Mesmo sem encontrá-la, mesmo que Pedro jamais voltasse" (...) Ninguém virá em meu socorro. Faz tanto tempo que invento meus próprios dias. Preciso começar por algum ponto" (p.120).

E este ponto vai se dar pela viagem, fora de São Paulo. A procura por Dulce Veiga incorpora um clichê de romance policial, o desejo de desvendar um segredo, revelar o desconhecido, que se transforma em viagem de busca existencial, de aprendizado. Do estrangeiro de molde existencialista, se comparando ao inseto de Kafka (p.53), o protagonista assume a condição real de estrangeiro, seja na margem contracultural, seja pela errância entediada, mudando por vários lugares. Uma vida em flashes. "À medida que o tempo passava, eu fugia, jamais um ano na mesma cidade, eu viajava para não manter laços — afetivos, gordurosos —, para não voltar nunca, e sempre acabava voltando para cidades que já não eram as mesmas, para pessoas de vida lineares, ordenadas, em cujo traçado definido não haveria mais lugar para mim” (p.56).

Ao chegar ao fim de sua procura, no centro do Brasil, é novamente a música que o conduz a Dulce Veiga. Súbito ouve uma voz de mulher. Acompanhando sem cantar, "comecei a caminhar mais depressa para encontrar aquela voz, e por falar em você, em razão de viver, você bem que podia me aparecer, e eu sempre tivera certeza que, desde o início, embora tudo pudesse continuar a ser somente loucura, vontade de voar, eu nada tinha a perder perseguindo uma canção, razão de viver" (p.198). A música muda a própria recepção do mundo, nem inferno, nem paraíso. Aceitar a vida na sua contingência. Dulce se confunde com o próprio protagonista. Ao falar de uma das últimas aparições de Dulce, antes da viagem, é de si que parece falar. "Ela não sente, não vê nem ouve nada além da própria canção que canta, endereçada a algo que já não existe nem está mais ali. Como um réquiem" (p.179). A busca da canção se traduz na busca de uma estória. É o que Dulce diz ao protagonista: "São tudo histórias, menino. A história que está sendo contada, cada um a transforma em outra, na história que quiser. Escolha, entre todas elas, aquela que seu coração mais gostar, e persiga-o até o fim do mundo. Mesmo que ninguém compreenda, como se fosse um combate" (p. 203-4). "Ao recusar dizer que o outro deve fazer, ao silenciar sobre isto, sua fala inquieta o outro". ${ }^{11}$ Sem ser exemplar, Dulce é mestre para o protagonista, no seu desejo de integridade: "chegar ao centro, sem partir-se em mil fragmentos pelo caminho. Completo, total. Sem deixar pedaço algum para trás” (p.180).

No último capítulo, domingo, dia de aniversário e renascimento do protagonista, ele encontra Dulce, mas só após passar pelo enfrentamento do temor da homossexualidade, ao beijar o ex-amante de Dulce, Saul, transformado em grotesco travesti da cantora (p.154), como numa referência ao antológico fim de Beijo no asfalto de Nelson Rodrigues, encenado anteriormente no próprio livro. "É preciso beijar meu

${ }^{11}$ NAZAR. Mais além da ilusão. 
próprio medo, pensei, para que ele se torne meu amigo", "é preciso ser capaz de amar meu nojo mais profundo para que ele mostre o caminho onde eu serei inteiramente eu" (p.190). E é Saul que revela o paradeiro de Dulce.

Dulce "não era mais bela, tornara-se outra coisa, mais que isso - talvez real" (p.199). No entanto, há ainda uma luz que a rodeia na sua última aparição, em carne e osso, em Estrela do Norte (p.213). É ela que grita alto o nome do protagonista. "Parecia meu nome. Bonito, era meu nome. E eu comecei a cantar" (p.213). Ele se transformara nela. Agora, ele era uma estrela. Me ajoelho.

Não há mais boa ou má literatura, bons ou maus filmes. Ou se há, não me importa mais. Há experiência e uma beleza impura. Há o protagonista. Há eu e você que me lê, que me ouve. Isto não basta, mas é um começo. Como a frase num calendário Seicho-No-Ie, os limites entre o sublime e o banal são frágeis: "Agora é o momento decisivo para renascer" (p.17). Não há mais nomes. Nomes sempre lembram outros nomes, não traduzem identidades, são máscaras na internet, aparências no mercado, ficções na noite e no dia, heterônimos frenéticos, sem história e densidade. O protagonista canta seu nome no final, mas não o diz. O escritor não o diz. Dulce e Márcia e Pedro, tantos outros personagens saem de cena. Agora é a sua vez ou qual é a sua voz?

\title{
A
}

\begin{abstract}
Can movies learn anything from literature? Without a theoretical discussion, the novel Onde andará Dulce Veiga? by Caio Fernando Abreu has answered this question. It represents a passage from a world of simulacrum, full of banal images and metatextual games so common in the 80's, to a desire of retold again ordinary stories, present in the 90's. Without a denial of mass media images, a contemporary narrative both in cinema and in literature is redefined by the search of an affective writing.
\end{abstract}

KEY-WORDS

cinema, literature, Caio Fernando Abreu 


\section{REFERÊNCIAS BIBLIOGRÁFICAS}

Abreu, Caio Fernando. Os dragões não conhecem o paraíso. São Paulo: Companhia das Letras, 1988.

Abreu, Caio Fernando. Ovelhas negras. 2. ed. Porto Alegre: Sulina, 1995.

Abreu, Caio Fernando. Onde andará Dulce Veiga?. 2. reimp. São Paulo: Companhia das Letras, 1997.

Avellar, José Carlos. O cego às avessas. In: Cinema. Rio de Janeiro, Associação de Críticos de Cinema do Rio de Janeiro, n.1, 1994.

Baudrillard, Jean. A arte da desaparição. Rio de Janeiro, Ed. UFRJ, 1997.

Benjamin, Walter. Experiência e Pobreza. In: Benjamin, Walter. Magia e Técnica, Arte e Política. São Paulo: Brasiliense, 1985.

Bernardet, Jean Claude. Os jovens paulistas. In: Bernardet, Jean Claude. O desafio do cinema. São Paulo: Jorge Zahar, 1985.

Costa, Jurandir Freire. Prefácio. In: Ortega, Francisco. Amizade e estética da existência. Rio de Janeiro: Graal, 1999.

ERIBOn, Didier. Michel Foucault e seus contemporâneos. Rio de Janeiro: Jorge Zahar, 1996.

Ferraz, Eucanãa. Morangos com Creme. In: Moriconi, Ítalo (org.). Caio Fernando Abreu - palavra e pessoa. (Manuscrito, 2000.)

Foucault, Michel. De l'amitié comme mode de vie. In: Foucault, Michel. Dits et écrits. vol. 4. Paris, Gallimard, 1994.

Golding, Nan. The ballad of sexual depedency. New York: Aperture Foundation, 1986.

Halperin, David. Saint Foucault. Oxford: Oxford University Press, 1995.

Koestenbaum, Wayne. Queen's throat. New York: Vintage, 1993.

Moreno, Antonio. A personagem homossexual no cinema brasileiro. Campinas: Unicamp, 1995. (Dissertação, Mestrado.)

Moriconi, Ítalo. Caio Fernando Abreu - palavra e pessoa. (Manuscrito, 2000.)

Morin, Edgar. As estrelas. Mito e sedução no cinema. Rio de Janeiro: José Olympio, 1989.

NazAr, Sérgio. Mais além da ilusão. In: Moriconi, Ítalo. Caio Fernando Abreu — palavra e pessoa. (Manuscrito, 2000.)

Ortega, Francisco. Para uma política da amizade. Rio de Janeiro: Relume Dumará, 2000.

Parente, André. Ensaios sobre o cinema do simulacro. Rio de Janeiro: Pazulin, 1998.

Peixoto, Nelson Brissac. Ver o invisível: a ética das imagens. In: Novaes, Adauto (org.). Ética. 5. reimp. São Paulo: Companhia das Letras, 1997.

Ramos, Fernão. A dama do Cine Shangai. In: Labaki, Amir (org.). O cinema dos anos 80. São Paulo: Brasiliense, 1991.

Silva, Wilson da. Uma poética do desejo: o cinema de Pedro Almodóvar na transição espanhola. São Paulo: Universidade de São Paulo, 1999. (Tese, Doutorado.)

Xavier, Ismail. O cinema brasileiro dos anos 90. In: Praga. n.9, jun. 2000. 